\title{
ESTRATEGIAS Y TOMA DE DECISIONES PARA LA EDUCACIÓN A DISTANCIA
}

Ligia María Angulo Hernández ${ }^{1}$

"Sabemos que la tecnología no es la solución para todos y cada uno de los problemas que enfrentan la educación y la capacitación, pero creemos que no se encontrarán soluciones permanentes sin tomar en cuenta el impacto de la tecnología". Lucent Technologies.

\section{Resumen}

Un buen proceso para la Educación a Distancia consiste en el desarrollo de varias etapas, entre ellas: diseño, desarrollo, evaluación y revisión. Su diseño no debe solamente considerar metas, necesidades y características de las y los estudiantes e instructoras(es), sino también compromisos técnicos.

El artículo presenta algunas de las estrategias y recursos tecnológicos actuales posibles de utilizar en las y los procesos de enseñanza y de aprendizaje desde la Educación a Distancia, recomendando a las universidades e instituciones darle prioridad a estos conceptos en busca de una Educación a Distancia de calidad.

\section{Abstract}

An excellent process for distance education consists of many stages of design, development, evaluation, and revision. The design has to take into account, not only, themes, needs, students' characteristics, instruction; but also, technological commitment.

This article explains some strategies and possible technological resources that can be used in the distance educational process. This article recommends to the

\footnotetext{
${ }^{1}$ Máster en Docencia, Licenciada en Ciencias de la Educación con énfasis en I y Il ciclos. Experiencia en Educación Primaria, Informática Educativa, Educación de Adultos. Actualmente es académica e investigadora de la División de Educación Rural.
} 
Universities and Educational Institutions to give priority to these concepts in order to offer high-quality education.

\section{Palabras claves}

Educación a Distancia, multimedia, recursos tecnológicos, calidad.

$\mathrm{E}$

mundo en que vivimos se caracteriza por ser dinámico, y lo que resulta valioso hoy, quizás mañana ya no lo sea; por ende, todas las organizaciones e instituciones requieren actualizar los recursos materiales con que trabajan y, lo más importante, capacitar el recurso humano para dar respuesta oportuna a los desafíos.

Las nuevas tecnologías como la World Wide Web y los multimedias tienen el potencial de ampliar el acceso a nuevos estudiantes y aumentar su flexibilidad. Estos son recursos que muchos consideran, se trabajan con niveles de aprendizajes "elevados" como el análisis, la síntesis, la resolución de problemas y la toma de decisiones. Las tecnologías se emplean para desarrollar destrezas en las y los estudiantes, para la búsqueda, el análisis y la interpretación de información relevante para su campo de estudio.

En estas circunstancias, los procedimientos y medios de la enseñanza tradicional y de aprendizaje se modifican, y la Educación a Distancia se hace necesaria para romper barreras de tiempo y espacio, al ofrecer a la sociedad métodos, técnicas y recursos efectivos y flexibles en el mundo cambiante.

La temática de la Educación a Distancia y su potencial como modalidad pedagógica es el tema que ocupa este espacio; un modelo que ofrece posibilidades de acceso a la formación, a las evoluciones tecnológicas, promueve el uso de medios de comunicación, incorpora formas organizativas para mejorar su acción y una integración de educación formal y no formal con el objetivo de optimizar su calidad.

En la actualidad, existe un interés particular por el concepto y modelo de Educación a Distancia, que llena una necesidad educativa ante tantos cambios tecnológicos y al que cada día más personas, de todos los niveles socioeconómicos, desean incorporarse, pues no sacrifican tiempo y dinero. Esto les permite ofrecer a sus familias mejorar la calidad de vida y estar al tanto del avance tecnológico.

Dado el nuevo contexto actual en la sociedad, es esencial para los centros universitarios hacer estudios sobre el costo y beneficio que ofrecen las tecnologías y sus recursos, así como la relación entre las diferentes aplicaciones tecnológicas y los resultados de aprendizaje, el equilibrio entre la docencia presencial, la virtual y su impacto en las y los estudiantes.

Los estudios sobre las estrategias de tutoría tipo 'on-line', diseño e implementación de materiales electrónicos, usos de 'software' de enseñanza y, 
sobre todo, lo que tiene relación con la gestión y las estructuras organizativas apropiadas para desarrollar y apoyar el aprendizaje que requiere de la tecnología, son aspectos por considerar en los estudios universitarios.

La aplicación de los recursos tecnológicos en la Educación a Distancia afecta la naturaleza del trabajo de las(os) educadoras(es) y su relación con las y los estudiantes. A medida que la tecnología va impregnando y cambiando el trabajo docente, se hace más importante definir la función de las universidades e identificar a quiénes les interesan estas características. Esta temática se aborda de una manera no exhaustiva en las siguientes anotaciones.

\section{a. Evolución de la teoría de la Educación a Distancia}

Existen importantes aportaciones teóricas que orientan la implementación de la Educación a Distancia; para algunos autores, la Educación a Distancia es considerada una disciplina, debido a que surge un conjunto de problemas cuando se aboca a su razonamiento. Otros dudan que sea una disciplina y ven la Educación a Distancia como "un campo distinto y coherente de una empresa educativa" (Keegan 1986:6); para Garrison, "no hay nada únicamente asociado con la educación a distancia en términos de sus metas, conducción de estudiantes o actividades que necesite afectar lo que denominamos educación" (1995). A pesar de las diferencias, los autores concuerdan en que la característica principal de esta modalidad es la separación entre docente y estudiantes.

En las últimas dos décadas, muchos aportes han surgido alrededor de las actividades en la Educación a Distancia; contribuciones de Otto Peters, Michael Moore, Borje Holmberg, Desmond Keegan, D. R. Garrison, John Verduim y Thomas Clark aportan sus ideas por separado desde seis marcos teóricos a las que llamaremos "Perspectivas Teóricas", que se presentan a manera de resumen en el cuadro comparativo de la siguiente página.

El cuadro muestra que el énfasis es la separación o distancia. Estas perspectivas teóricas resaltan la influencia de la educación de adultos, donde el que aprende es importante, así como el tema de la comunicación.

Para Peters, la organización y funcionamiento de la institución o programa de Educación a Distancia es primordial, y la separación entre la y el que educa y la educanda y el educando se debe a las características de una sociedad industrial, donde los materiales didácticos y productos se producen para una sociedad global. Peters visualiza el concepto de la distancia como algo más que la distancia geográfica. Menciona, como ejemplo, la estandarización de materiales didácticos, tecnología más individualizada y descentralizada de la estructura de toma de decisiones. 


\section{Perspectivas teóricas de la Educación a Distancia}

\begin{tabular}{|c|c|c|c|}
\hline Marco & $\begin{array}{l}\text { Conceptos } \\
\text { centrales }\end{array}$ & Foco principal & Influencia posible \\
\hline Peters (1967) & $\begin{array}{l}\text { Industria posindus- } \\
\text { trial }\end{array}$ & $\begin{array}{l}\text { Empate con principios } \\
\text { y valores sociales }\end{array}$ & Sociología cultural \\
\hline Moore (1983) & $\begin{array}{l}\text { Distancia transac- } \\
\text { cional }\end{array}$ & $\begin{array}{l}\text { Necesidades y de- } \\
\text { seos percibidos del } \\
\text { aprendiz }\end{array}$ & Estudio independiente \\
\hline Holmberg (1983) & $\begin{array}{l}\text { Autonomía del } \\
\text { aprendiz. } \\
\text { Comunicación con- } \\
\text { tinua. } \\
\text { Conversación didácti- } \\
\text { ca guiada }\end{array}$ & $\begin{array}{l}\text { Promoción del apren- } \\
\text { diz vía métodos per- } \\
\text { sonales y convencio- } \\
\text { nales }\end{array}$ & $\begin{array}{l}\text { Enfoque humanista } \\
\text { de la educación }\end{array}$ \\
\hline Keegan (1986-1990) & $\begin{array}{l}\text { Reintegración de los } \\
\text { actos de enseñanza y } \\
\text { aprendizaje }\end{array}$ & $\begin{array}{l}\text { Recreación de com- } \\
\text { ponentes interperso- } \\
\text { nales de la enseñanza } \\
\text { cara a cara }\end{array}$ & $\begin{array}{l}\text { Marco de la pedago- } \\
\text { gía tradicional }\end{array}$ \\
\hline Garrison (1987) & $\begin{array}{l}\text { Transacción educa- } \\
\text { tiva. } \\
\text { Control del aprendiz. } \\
\text { Comunicación }\end{array}$ & $\begin{array}{l}\text { Facilitación de la } \\
\text { transacción educativa }\end{array}$ & $\begin{array}{l}\text { Teoría de la comuni- } \\
\text { cación. } \\
\text { Principios de la edu- } \\
\text { cación de adultos }\end{array}$ \\
\hline $\begin{array}{l}\text { Verduim y Clark } \\
\text { (1991) }\end{array}$ & $\begin{array}{l}\text { Diálogo/soporte es- } \\
\text { tructura/ } \\
\text { Competencia especia- } \\
\text { lizada/ } \\
\text { Competencia general/ } \\
\text { autodirección }\end{array}$ & $\begin{array}{l}\text { Requisitos de la tarea } \\
\text { del aprendiz }\end{array}$ & $\begin{array}{l}\text { Principios de la edu- } \\
\text { cación de adultos. } \\
\text { Estructuras del cono- } \\
\text { cimiento }\end{array}$ \\
\hline
\end{tabular}

Fuente: Amundsen, Cheryl en su artículo "Evolución de la teoría de la educación a distancia". 1993.

Moore señala que la distancia es una oportunidad para aumentar la autonomía en el aprendiz, el cual lo ve como un aspecto positivo. Agrega que la distancia no es algo solamente geográfico, sino que es la separación o distancia del aprendiz de la institución y los aspectos sociales.

Holmberg la ve como un medio para incrementar el interés, motivación e involucramiento del aprendiz, fortaleciendo la autonomía de quien aprende; sin 
embargo, para Keegan es algo que desconecta a la(al) maestra(o) de quien aprende y de la enseñanza y el aprendizaje. Esta última situación requiere ser superada para no perder de vista aspectos interpersonales durante el proceso.

Verduim y Garrison enfatizan en la necesidad de la presencia de la tecnología para facilitar la comunicación bilateral maestra(o)-alumna(o). Su teoría no parece darle importancia a la idea y al concepto de la distancia, pero sí enfatizan que la Educación a Distancia requiere de una comunicación bilateral y colaborativa entre educadora o educador y educanda o educando. Ambos autores incursionan en su pensamiento el considerar la naturaleza de los materiales que utiliza la(el) educanda(o) en el proceso de aprendizaje.

Por otro lado, Verduim señala que este modelo puede relacionarse con la educación de adultas(os) de tipo convencional, por lo que considera en su teoría los principios de la Andragogía. Incluye, además, que el diálogo es el soporte para la persona que aprende, abarcando desde las simples instrucciones para desarrollar tareas como un soporte de motivación y emoción.

Todas estas teorías de la Educación a Distancia presentan la noción de distancia como eje central, pero el significado de su importancia se relaciona con el aprendizaje deseado y las implicaciones que pueda tener en los roles de la enseñanza, métodos instruccionales y expectativas de la educanda y el educando.

\section{b. Panorama de la Educación a Distancia en la sociedad del conocimiento}

Los postulados teóricos de la historia de la Educación a Distancia se remontan al siglo XIX, cuando la disponibilidad de ferrocarriles y correo de bajo costo y la difusión en los Estados Unidos y Europa permitió que universidades y otras instituciones promovieran la educación lejos de sus sedes centrales. A este modelo se le conoció como "Educación por correspondencia", un modelo positivo, aunque debemos citar aspectos negativos como su comercialización.

Actualmente encontramos "universidades duales", con una planta académica convencional, infraestructura física con laboratorios, bibliotecas y centros de cómputo y que desarrollan actividades de Educación a Distancia. Estas universidades tienen responsabilidades ante la sociedad, pues su viabilidad e independencia son influenciadas por el acceso y creación del nuevo conocimiento. Para ello requieren profesionales activas(os) que conformen equipos de trabajo flexibles y multidisciplinarios, y apliquen el concepto de "universidad corporativa", donde estas universidades pueden encontrarse en distintas ciudades, pero relacionadas entre sí. 


\section{c. Medios y tecnología aplicables para la Educación a Distancia}

Un factor importante en el campo de la Educación a Distancia tiene relación con el uso de los medios de comunicación. Cabe señalar que el papel de los medios no es simplemente complementario o de apoyo, sino más bien se trata de una consideración integrada de medios, bajo un papel más primario que secundario. De acuerdo con el uso que le ha dado la unidad de profesionales de la Educación a Distancia, la tendencia más común en nuestros días es denominarla como Tecnología de la Información y Comunicación (TIC). Estos medios y tecnología se mencionan a continuación, rescatando sólo su aplicación y dejando de lado, en esta oportunidad, sus aportes positivos o negativos, ya que ameritan un tratado independiente y queda sujeto a numerosas controversias.

- Medios impresos: forman el soporte original de la Educación a Distancia y siguen siendo valiosos y apreciados. Son considerados el vínculo más importante entre la(el) alumna(o), el conocimiento y la asesora o el asesor. Es la fuente de información a la que atenderá el o la estudiante que no cuenta con el apoyo de la o el docente presencial. Los medios impresos son el vínculo con las experiencias para adquirir conocimiento, habilidades y competencias. Existen distintos tipos de materiales, que se presentan en varios formatos: las guías de estudio, antologías, textos programados o de autoestudio, apuntes o cuadernos de trabajo, artículos, manuales, entre otros. Para el diseño de cualquier material escrito, es pertinente partir de la concepción teórica de aprendizaje; es decir, preguntarse qué corriente o teoría del aprendizaje se considera representa nuestra forma de enseñar: conductismo, cognoscitivismo, construccionismo, para mencionar algunos.

- Radio y televisión: la radio permite alcanzar poblaciones que no pueden asistir a la escuela y complementar con la voz los materiales escritos. La radio digital y por vía satelital permiten ampliar su alcance. La televisión tiene un gran impacto en la educación, por la forma en que se recibe la información, su formato y su calidad de imagen. La televisión por cable y por satélite están en aumento y, por ende, el gran alcance geográfico local, regional, nacional e internacional. Útil para localidades pequeñas o muy aisladas, con bajo costo, simplicidad de operación, marco regulatorio, entre otros aspectos.

- Correo electrónico: se inició con la Internet, por el intercambio de mensajes entre investigadoras(es), tutora o tutor y estudiantes; además, el intercambio de documentos, como artículos, tareas, ejercicios u otros. Tanto la tutora o el tutor como las y los estudiantes pueden crear y revisar tareas 
cuando lo deseen, contestar preguntas hechas sobre programas educativos o asignaturas; brindar aclaraciones sobre la realización de algún ejercicio o forma de estudio.

- Lista de distribución: llamados Foros de discusión, donde las personas que deseen participar se suscriben e identifican por medio de un "alias" o "login" de su dirección electrónica. Su función es la de reunirse virtualmente con otras personas que participan en un curso desde diferentes ámbitos geográficos para intercambiar ideas, informaciones, experiencias y trabajos. Algunos usos son: actualización de la información sobre un tema particular, diseño y trabajos en proyectos, solicitud de asesoría u orientación, análisis de diversas perspectivas, discusión de casos, diagnósticos y soluciones, entre otros. Para ingresar a un grupo de discusión (Foro de discusión), se accede desde la web. Las y los participantes están ordenadas(os) por temáticas de participación y respuestas. Utilizan un lenguaje html, que permite la inclusión de imágenes, sonidos, colores y vínculos, que pueden ser vistos desde cualquier computadora del mundo que se encuentre conectada a Internet.

- Multimedia, CD-Rom: la tecnología multimedia o de CD-Rom se usa como apoyo a la enseñanza en las aulas. Los laboratorios de idiomas, el diseño asistido por un ordenador en arquitectura, la simulación de experimentos científicos y de grandes bases de datos de investigación, los programas matemáticos y estadísticos contienen recursos multimedia como gráficos, vídeo y audiocomprimidos.

- Chat: sistema de comunicación sincrónica en Internet, donde las(os) usuarias(os) se pueden conectar y charlar entre sí para realizar actividades conjuntas entre alumno-alumno, alumno-tutor. Discusión colectiva, evaluar las y los participantes, realizar preguntas y socializarse. Los chats son conocidos por su tipo "talk-on-line".

- Videoconferencia: comunicación bidireccional y sincrónica de imagen, sonido y datos. Sus usos educativos son los estudios de casos, entrevistas, exposiciones, dinámicas grupales, presentación de proyectos, evaluaciones y técnicas de socialización que se dan con gran naturalidad y permite concebir el conjunto de aulas conectadas, como una sola gran aula 'virtual'.

- Audioconferencia: es el enlace entre varias(os) participantes o grupos de participantes por teléfono, de manera que pueden realizar un encuentro a distancia. Se usa para entrevistas, evaluaciones, ampliación de temas, estudio de casos, solución a problemas, entre otros.

- Internet: espacio de la red mundial de computadoras conocido también como ciberespacio, forma de relación interpersonal, intercambio de información, de ideas, cultura, valores y sentimientos. En el año 2003, se 
estimó que 600 millones de personas se conectaron a la Internet en busca de múltiples fuentes de información gráfica, icónica, auditiva y personal. Aproximadamente existen más de 320 millones de páginas en Internet, esta es la mayor fuente de información en el mundo ${ }^{2}$. Esto significa que universidades, gobiernos, hogares, instituciones, académicas(os), estudiantes, negocios, no deben desaprovechar el recurso. Sin embargo, puede decirse que la Internet no sustituirá a las y los docentes, sino que es un instrumento que se suma a la lista de recursos educativos.

- Bibliotecas digitales: la(el) usuaria(o) a distancia requiere de información que está almacenada y accesible en bibliotecas, hemerotecas y archivos, sin verse obligada(o) a asistir a ellos. Este aporte es lo que se llama bibliotecas digitales o bibliotecas virtuales. Aquí pueden encontrarse textos completos, tablas de datos, imágenes fijas como dibujos, fotografías y pinturas, mapas, videos, archivos de sonido, reconstrucciones digitales de objetos tridimensionales, entre otros. Es posible su consulta y navegar en estos acervos a través de redes de comunicación.

\section{d. Consideraciones finales para la toma de decisiones}

\section{- El alcance social de la Educación a Distancia}

Existen sectores de la sociedad con motivación y capacidad suficiente para iniciar sus estudios o para continuar con ellos, pero por sus condiciones especiales no tienen acceso a ellos; algunas de estas personas las encontramos en zonas geográficas alejadas, otras no pueden acudir a una institución por su condición laboral; existen también mujeres a las que se les dificulta el estudio por su responsabilidad familiar, personas hospitalizadas, reclusas(os), emigrantes, entre otros.

Hoy más personas utilizan productos multimedia. Programas educativos o de difusión, juegos y materiales de referencia como enciclopedias virtuales, entre otros productos, son el resultado de integrar textos, sonidos, imágenes, animaciones y video en un solo producto, al que se puede tener acceso en un disco compacto o en Internet. La experiencia con esta clase de materiales favorece y motiva la consulta y uso de la información. Aspecto que las universidades que utilizan la modalidad de Educación a Distancia deben considerar como parte importante en el estudio y la difusión de esta alternativa tecnológica.

\footnotetext{
2 Dato tomado de la dirección electrónica: http://www.aui.es/estadi/internacional/internacional.htm\#Uso_ internet_mundo(consultado 26/05/2003)
} 
La población activa requiere de buenas destrezas de comunicación (leer, hablar y escuchar), capacidad para aprender independiente, destrezas sociales (ética, actitud positiva y responsable), destrezas para el trabajo en equipo, capacidad para adaptarse a circunstancias cambiantes, destrezas de razonamiento (resolución de problemas; destrezas críticas, lógicas y numéricas), navegación en los conocimientos (saber dónde conseguir la información y cómo procesarla) y habilidades y capacidades posibles de desarrollar en un modelo de Educación a Distancia.

\section{- Educación a Distancia desde el aspecto de la Educación Virtual}

La capacidad de integrar la Educación a Distancia con diversos medios a través de la computadora da como resultado una tecnología 'potente', pues su desarrollo y puesta en práctica requiere que participen especialistas, lo que señala la importancia de trabajar en equipos de desarrollo multidisciplinarios. Equipos que requieren identificar desde sus puestos e instituciones elementos básicos para desarrollarlos, analizar las técnicas y procedimientos acordes con sus objetivos, así como las ventajas y desventajas que los productos en este sistema ofrecen.

La Educación Virtual supera los límites del aula al evitar desplazamientos y un uso flexible del tiempo por parte de la y del estudiante. El componente formativo va acompañado por procesos de autocontrol y autonomía de las y los estudiantes, al permitirles adaptarse al modo de aprender de cada alumno. El tiempo para meditar las respuestas y organizarlas se incrementa, así como la capacidad de llevarlas a un pensamiento crítico y poner a prueba sus capacidades y habilidades personales.

\section{- El cambio tecnológico en los centros universitarios}

Para aplicar las nuevas tecnologías en un centro universitario, se necesita más que comprar computadoras y crear sitios web. El éxito del uso de la tecnología en la enseñanza y el aprendizaje depende también de la capacidad de introducir cambios en la cultura docente y organizativa. Se requieren más que estrategias para gestionar el cambio, garantizar el éxito en el uso de la tecnología y motivar al profesorado para su aplicación.

Tanto las(os) académicas(os), administrativas(os), como las y los estudiantes de los centros universitarios deben saber como acceder a la información (buscarla y bajarla) de muchas fuentes y en múltiples formatos; incorporar en los documentos de trabajo material al que hayan accedido o que hayan reelaborado; 
compartirlos, crearlos o transmitirlos según sea necesario. Si aceptamos todo esto como elementos del diseño de la enseñanza y del aprendizaje, entonces, hay que construir sistemas que lo apoyen, tanto para el aprendizaje formal como el no formal.

En la actualidad, se cuenta con una red de cómputo llamada Internet2; su origen se basa en el espíritu de colaboración entre universidades y su objetivo es desarrollar aplicaciones telemáticas para facilitar procesos de investigación y educación entre universidades, formar personal capacitado en el uso y manejo de redes avanzadas de cómputo. Se espera que las aplicaciones y el nuevo hardware que se desarrolle ayuden a la velocidad de la red y aumente de manera considerable y la transmisión multimedia sea una realidad, pues Internet2 funciona 100 veces más rápida que la conexión www (World Wide Web).

\section{e. Reflexión final}

La Educación a Distancia se compone de varios elementos que la caracterizan, donde se aplican diversas metodologías educativas para producir aprendizajes. Esta modalidad educativa, poco a poco, se va introduciendo e imponiendo con más fuerza en la educación superior como una de las alternativas ante los retos educativos que enfrenta la educación presencial.

Toda acción que mejore y brinde oportunidades de enseñanza debe referirse a la(al) educanda(o), conocer sus antecedentes, motivaciones, intereses, estilos de aprendizajes, ambiente de estudio y valores, aspectos básicos para cualquier decisión en la Educación a Distancia. Estas estrategias y decisiones deberán contemplar que la o el estudiante de esta modalidad de enseñanza es una(un) adulta(o) física y mentalmente, que cuando ha decidido estudiar, sabe qué quiere y busca. Algunas veces puede carecer de estrategias de estudio y formas de motivarse, pero cuando esto sucede, corresponde a las y los responsables de la opción de enseñanza, desarrollar, buscar estrategias y tomar decisiones de calidad que le permitan llegar al éxito.

La toma de decisiones debe considerar el equilibrio entre el acceso, costos y calidad desde el punto de vista del emisor y el receptor. Hay que tomar en cuenta que en la actualidad se requiere aprender para tener más y mejores oportunidades; aprender para tener mejor comunicación con el entorno; aprender para socializarnos; aprender y saber más en tiempo y espacios adecuados a las posibilidades de cada quien. 


\section{Referencias}

Amundsen, Cheryl. (1993). "The evolution of theory in distance education". En Desmond Keegan (Ed.). Theoretical principles of distance education. Great Britain: Routledge, 1993, 61-79. Traducción: Jorge Méndez.

Barrón, Héctor S. (1996). La educación en línea y el texto didáctico. Universidad Nacional Autónoma de México (UNAM). México, D.F.

Bates, A.W. (2001). Cómo gestionar el cambio tecnológico. Estrategias para los responsables de centros universitarios. Barcelona: Ediuoc-Gedisa.

Garrison, D.R. (1995). "Three generations of technological innovations in distance education". Distance Education 6(2), 235-41.

Keegan, D.J. (1986). The foundations of Distance Education. London: Croom Helm (1990). Foundations of Distance Education (2. edn.) London: Routledge.

Méndez, Jorge. (2004). Videoconferencia grupal. Estructura de la comunicación y diseño instruccional. Documento electrónico. CUAED-UNAM.

Pisanty, Alejandra. (2000). "Dos taxonomías de los medios técnicos para la educación a distancia". En: Revista Digital Universitaria, volumen 1, $\mathrm{N}^{\circ} 0$. Dirección General de Servicios de Cómputo Académico-UNAM-Ciudad Universitaria, México, D.F.

Roquet García, Guillermo. (1998). Los foros de discusión en educación. Siglo XXI: Perspectiva de la educación a distancia desde América, año 4, $\mathrm{N}^{\circ} 10,69-78$.

Roquet García, Guillermo. (2004). Los chats y su uso en educación. Documento electrónico. CUAED-UNAM. 